\title{
Influence of the Quenching Temperature on the Phase Composition, Structure, and Wear Resistance of 150XHM Steel
}

\author{
M. A. Filippov, M. A. Gervas'ev, Yu. V. Khudorozhkova, and V. V. Legchilo \\ Ural Federal University \\ Received September 23, 2013
}

\begin{abstract}
The influence of the quenching temperature on the quantity of residual austenite, its stability, and its ease of deformational martensitic transformation in 150XHM steel is studied. In the addition, the hardening and abrasive-wear resistance of the steel are studied as a function of the quenching temperature. The dependences of the steel's hardening and wear resistance on the quenching temperature are of opposite form. The drop in hardness with increase in quenching temperature is due to increase in the content of residual austenite. At the same time, the relative ease of deformational martensitic transformation in the metastable residual austenite results in increase in wear resistance and microhardness of the worn surface.
\end{abstract}

Keywords: abrasive wear, quenching temperature, metastable residual austenite, deformation-induced martensite, strain hardening

DOI: $10.3103 / \mathrm{S} 0967091213110065$

The prevention of abrasive wear is of great importance, since such wear can cause premature failure of components in mining, metallurgical, construction, and drilling equipment. We are particularly interested in the cylindrical bushes of borehole pumps, which are subject to cyclic loads at high variable pressure, as well as the abrasive action of borehole fluid with suspended solid particles. The complex loading results in rapid bush failure, on account of hydroabrasive wear and the appearance of impermissible gaps in the bush-piston assembly.

In the present work, in connection with the development of a production process for cylindrical 150XHM steel bushes of borehole pumps, we study the influence of the quenching temperature (in the range $850-1175^{\circ} \mathrm{C}$ ) on the wear resistance, in combination with the structural strength of the bushes. The bushes are held at the specified temperature for $30 \mathrm{~min}$, with subsequent cooling in oil.

We study the microstructure and abrasive-wear resistance on $10 \times 10 \times 25 \mathrm{~mm}$ samples taken from cast 150XHM steel pipe blanks after normalization and tempering.

The wear resistance of the $150 \mathrm{XHM}$ steel samples is estimated on special equipment based on a planing machine. Samples with a $10 \times 10 \mathrm{~mm}$ working area perform reciprocating motion over corundum-based 14A32MN481 abrasive paper (State Standard GOST 6456-82). The length of a single working pass is $0.135 \mathrm{~m}$; the frictional path in a single

\footnotetext{
${ }^{1}$ V.V. Yurovskikh (OAO Uralmashzavod) took part in these procedures.
}

test at $0.158 \mathrm{~m} / \mathrm{s}$ is $120 \mathrm{~m}$. The normal load on the sample is $10 \mathrm{~kg}$ (unit load $1 \mathrm{MPa}$ ). The transverse displacement of the abrasive paper in a double pass is $1.2 \mathrm{~mm}$. The abrasive-wear resistance is determined from two parallel tests with the 150XHM steel samples and a standard sample (9X5MФC roller steel). The comparison is based on the relative wear resistance

$$
J=\Delta M_{\mathrm{st}} / \Delta M_{\mathrm{sa}},
$$

where $\Delta M_{\mathrm{st}}$ is the mass loss of the standard 9X5МФC roller steel sample after quenching from $900^{\circ} \mathrm{C}$ and low tempering $\left(\Delta M_{\mathrm{st}}=0.4100 \mathrm{~g}\right) ; \Delta M_{\mathrm{sa}}$ is the mass loss of the tested sample.

To obtain more complete information regarding the life of 150XHM steel in abrasive wear, each sample is tested in two conditions:

-with rigorous friction on fresh 14A32MN481 abrasive paper (mean particle size $140 \mu \mathrm{m}$ );

-with moderate friction on repeatedly used 14A32MN481 abrasive paper (mean particle size $40 \mu \mathrm{m})$.

The samples are tested with constant unit load $1 \mathrm{MPa}$ on two 30-m segments of frictional path.

The initial sample structure consists of tempering sorbite, nonuniformly distributed sections of carbide eutectic (ledeburite; around 5\%, on average), and secondary cementite along the grain boundaries (Fig. 1a), with a mean hardness of $300 \mathrm{HV}$.

After quenching from $850^{\circ} \mathrm{C}$, the structure contains not only martensite but excess cementite (Fig. 1b). After quenching from $1000^{\circ} \mathrm{C}$, the structure consists of fine martensite needles with intragrain car- 

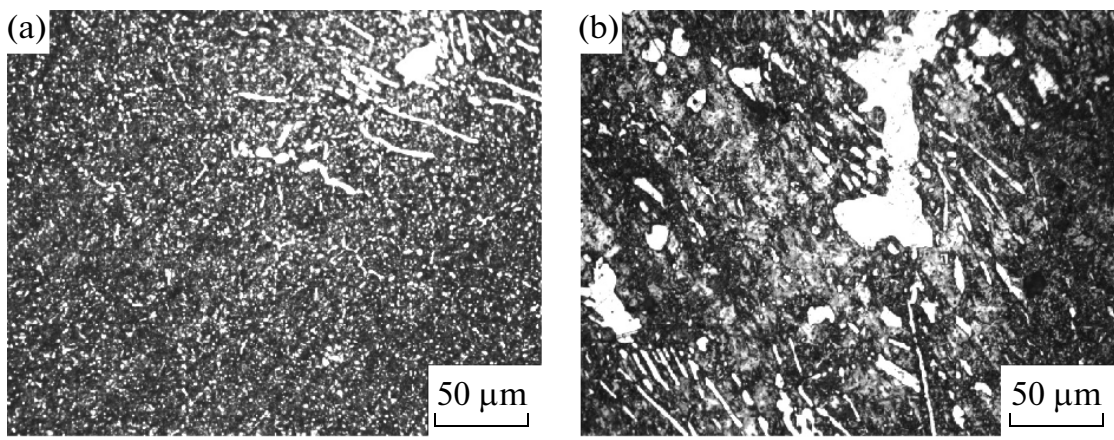
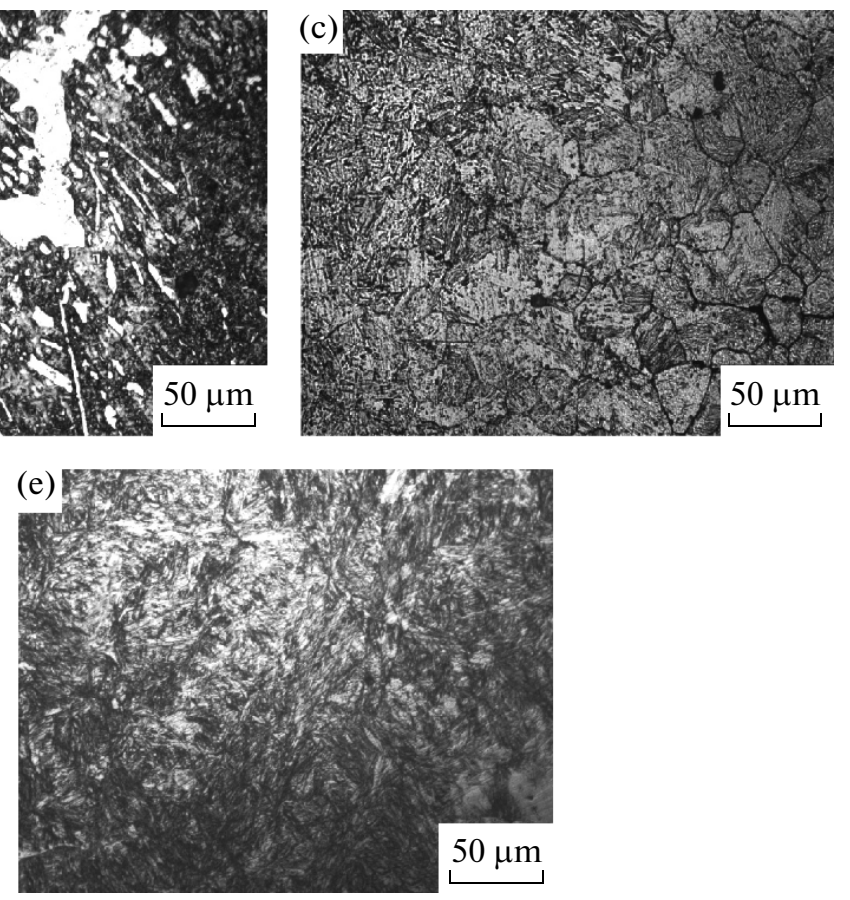

$0 \mu \mathrm{m}$

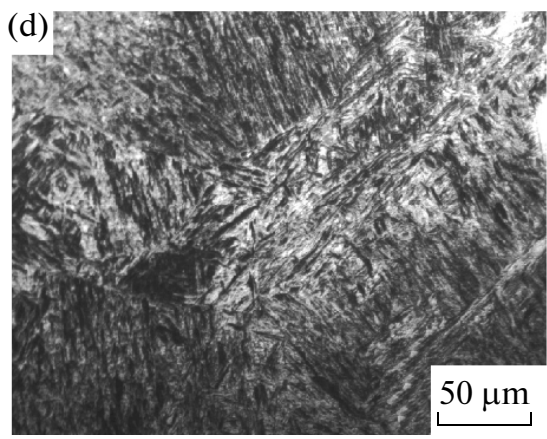

Fig. 1. Microstructure of $150 \mathrm{XHM}$ steel without quenching (a) and after quenching from $850^{\circ} \mathrm{C}(\mathrm{b}), 1000^{\circ} \mathrm{C}(\mathrm{c}), 1100^{\circ} \mathrm{C}(\mathrm{d})$, and $1175^{\circ} \mathrm{C}(\mathrm{e})$.
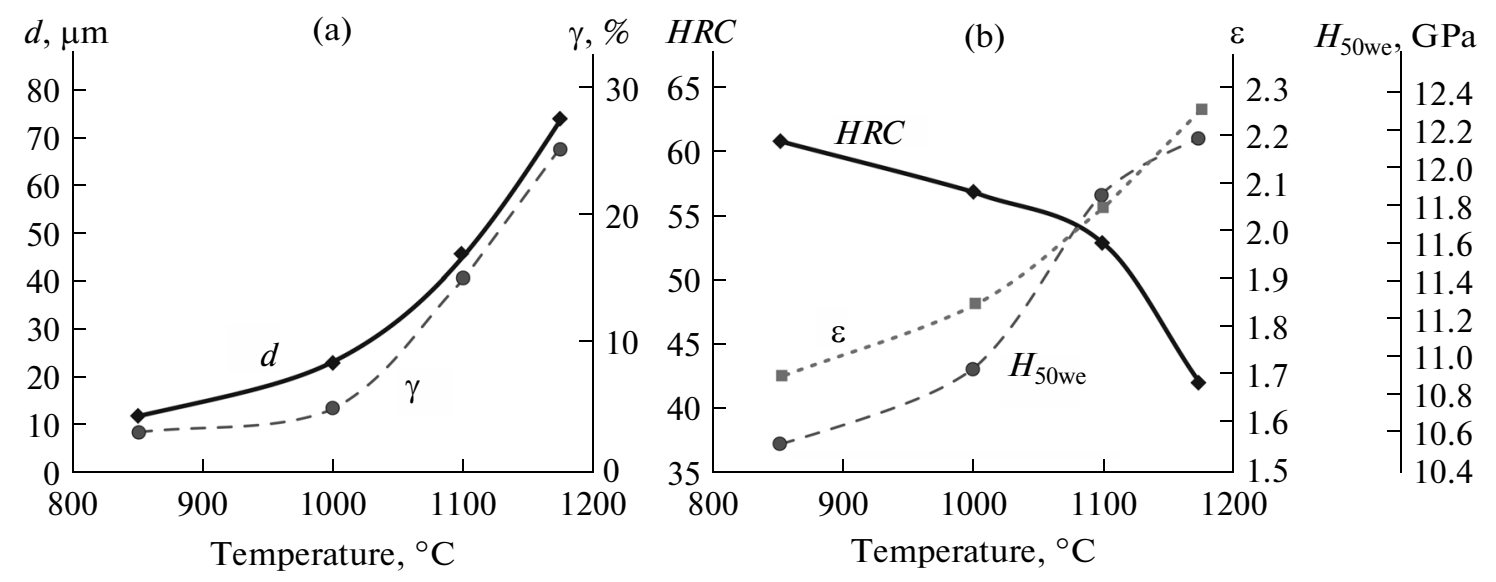

Fig. 2. Influence of the quenching temperature of 150XHM steel on the grain size $d$ and quantity $\gamma$ of residual austenite (a) and on the hardness $H R C$, relative abrasive-wear resistance $\varepsilon$, and microhardness $H_{50}$ we at the wear surface.

bides and a broken cementite grid (Fig. 1c). After quenching from $1100^{\circ} \mathrm{C}$, there are still some traces of the cementite grid; the martensite needles are large (Fig. 1d). After quenching from $1175^{\circ} \mathrm{C}$, we see sections of residual phase-hardened austenite (up to $10 \mu \mathrm{m})$, with microhardness around $4 \mathrm{GPa}\left(H_{20}\right)$, between martensite crystals with microhardness around $9 \mathrm{GPa}$ (Fig. 1e).

We also consider the influence of the quenching temperature on the austenite grain size (Fig. 2a). With increase in temperature, the grain size increases. The increase is especially pronounced for temperatures above $1000^{\circ} \mathrm{C}$, on account of vigorous solution of the secondary-cementite grid (Fig. 1c).

We already know that, with increase in quenching temperature, the morphology of the martensite in 9X5МФC steel changes. Above $1000^{\circ} \mathrm{C}$, rack martensite is gradually converted to twins [2].

With increase in quenching temperature, secondary carbides of type $(\mathrm{Fe}, \mathrm{Cr})_{3} \mathrm{C}$ steadily dissolve, and 


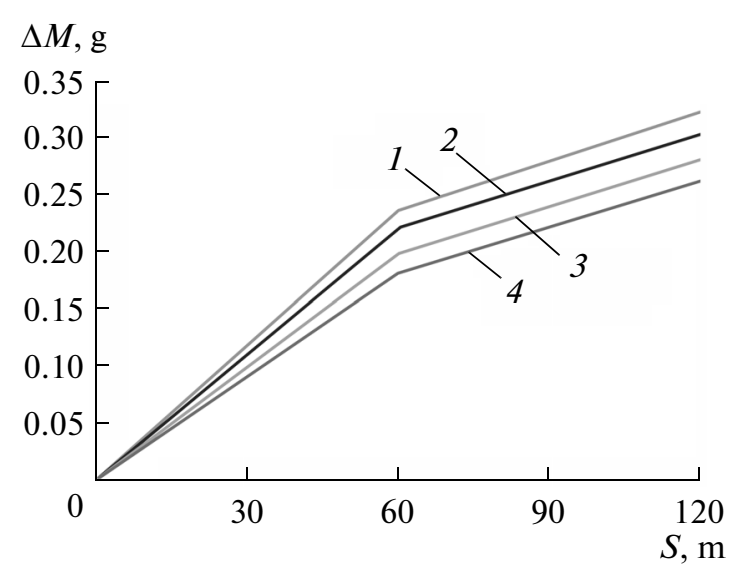

Fig. 3. Mass loss of $150 \mathrm{XHM}$ steel samples in abrasive wear after quenching from $850^{\circ} \mathrm{C}(1), 950^{\circ} \mathrm{C}(2), 1100^{\circ} \mathrm{C}(3)$, and $1175^{\circ} \mathrm{C}(4)$.

the solid solution is saturated with carbon and chromium. That increases the quantity of residual austenite from 0 at $t_{\mathrm{qu}}=850^{\circ} \mathrm{C}$ to $25 \%$ at $t_{\mathrm{qu}}=1175^{\circ} \mathrm{C}$ (Fig. 2a). There will be corresponding decrease in hardness, which is slight at first. On account of increase in the quantity of residual austenite after quenching from $1100^{\circ} \mathrm{C}$ and above, the hardness declines from $53 \mathrm{HRC}$ at $t_{\mathrm{qu}}=1100^{\circ} \mathrm{C}$ to $42 \mathrm{HRC}$ at $t_{\mathrm{qu}}=1175^{\circ} \mathrm{C}$ (Fig. 2b). The hardness depends on the balance of two opposing factors:

-increase in the content of residual austenite, which reduces the hardness;

-increase in the carbon content in the martensite, which increases the hardness.

At quenching temperatures above $850^{\circ} \mathrm{C}$, the first factor predominates, and the hardness of the steel is reduced on quenching.

The saturation of austenite with carbon and alloying elements in high-temperature quenching leads to increased stability of supercooled austenite, decrease in the critical quenching rate, and hence increased hardenability.

In contrast to the hardness, the wear resistance of 150XHM steel increases with increase in the quenching temperature, in both rigorous $(0-60 \mathrm{~m})$ and moderate $(60-120 \mathrm{~m})$ test conditions (Fig. 3).

Our findings regarding the influence of $t_{\mathrm{qu}}$ on the wear resistance of $150 \mathrm{XHM}$ steel are consistent with literature data indicating that residual austenite of a particular composition, which is metastable with respect to deformational martensitic transformation, plays a positive role in ensuring high abrasive-wear resistance [1]. The wear resistance increases because the quantity of high-carbon deformational $\alpha$ martensite at the wear surface increases with increase in $t_{\text {qu }}$ and the residual austenite becomes more susceptible to frictional hardening (Fig. 2b).
The wear resistance of 150XHM steel is greatest after quenching from $1175^{\circ} \mathrm{C}$. In Fig. $2 b$, we see a correlation between the maximum wear resistance of 150XHM steel and the microhardness of the working surface after wear. Accordingly, the wear resistance may expediently be estimated on the basis of the effective microhardness $H V_{\text {eff }}$, which consists of the initial microhardness $H V_{0}$ and the increment $\Delta H V$ at the wear surface: $H V_{\text {eff }}=H V_{0}+\Delta H V$ [3]. The effective microhardness characterizes the strength of the steel's surface layer, on the basis not only of the initial hardness but also the hardening due to phase transformations in the course of wear and the strain hardening of the existing and newly formed phases - in particular, hardening due to the formation of deformational martensite.

The role of $H V_{\text {eff }}$ in the wear resistance may be seen for the example of 150XHM steel: after quenching from $1175^{\circ} \mathrm{C}$, it has minimum initial hardness, but its abrasive-wear resistance is a maximum. That is associated with the ease of strain hardening of the metastable residual austenite and the carbon martensite; the corresponding increment in the microhardness of the sample's working surface corresponds to $H V_{50} \sim 7.5 \mathrm{GPa}$ (Fig. 2b). High-temperature quenching produces a dissipative microheterogeneous structure that contains metastable austenite, which is converted to disperse martensite under the action of the abrasive. That microheterogeneous structure efficiently scatters the energy supplied to the working surface on account of relaxation processes. Martensite is formed, with considerable strain hardening of the surface layer; compressive stress also appears. The result is high abrasivewear resistance.

\section{CONCLUSIONS}

The microstructure of $150 \mathrm{XHM}$ roller steel obtained after quenching from the standard temperature $\left(850^{\circ} \mathrm{C}\right)$, which consists of fine martensite needles with excess carbides, ensures high hardness $(61 H R C)$. However, the abrasive-wear resistance could be higher.

Increasing the quenching temperature to $1100-$ $1175^{\circ} \mathrm{C}$ significantly affects the steel structure: the austenite grains and martensite crystals are enlarged; and the initial hardness is progressively reduced (to 42 HRC) on account of solution of some of the carbides and corresponding increase in the content of residual austenite to $25 \%$. However, this is accompanied by increase in abrasive-wear resistance.

The residual austenite obtained as a result of hightemperature quenching of $150 \mathrm{XHM}$ steel (1100$1175^{\circ} \mathrm{C}$ ) is metastable and is converted to deformation-induced martensite in the course of wear. That results in maximum wear resistance, since the working surface readily undergoes frictional hardening. 
In terms of abrasive-wear resistance, the optimal quenching temperature of 150XHM steel is 1100$1150^{\circ} \mathrm{C}$, where martensite-carbide structure with metastable residual austenite is formed. Further increase in quenching temperature is inexpedient, on account of excessive increase in grain size.

\section{REFERENCES}

1. Filippov, M.A., Litvinov, V.S., and Nemirovskii, Yu.R., Stali s metastabil'nym austenitom (Steel with Metastable Austenite), Moscow: Metallurgiya, 1989.
2. Gervas'ev, M.A., Khudorozhkova, Yu.V., and Filippov, M.A., Mekhan. Term. Obrab. Met., 2010, no. 10, pp. $16-20$.

3. Korshunov, L.G., Frictional wear of metals, Metallovedenie i termicheskaya obrabotka stali (Physical Metallurgy and Heat Treatment of Steel), Bernshtein, M.L. and Rakhsthtadt, A.G., Eds., Moscow: Metallurgiya, 1991, vol. 1, part 2, pp. 387-413.

Translated by Bernard Gilbert 